\title{
Promoting Food Safety and Food Security in Rural Tourism Destination
}

\author{
N. Sikhiram ${ }^{1}$ \\ ${ }^{1}$ Faculty of Humanities, Chiang Mai University, 50200 Chiang Mai, Thailand
}

\begin{abstract}
This study was conducted at two villages, Ban Mae Kampong, Mae On, Chiang Mai and Ban Pa Miang, Muang, Lampang, Northern Thailand. This community is supported by Thai government tourism ministry to develop their skills in order to create and offer rural tourism. The study focus on community member groups who are involved with rural tourism activities; Homestay members, food preparation management members, tour guides, community leader groups, in order to assess the acceptance, collaboration and preparation of safety indigenous food menu and food security management where will support rural tourism community objectives. This study was carried out as in a participatory stage which included various seminars and workshops of rural tourism management concluded from homestay services, Thai herbs medication beneficiary, basic and applied nutrition concepts, indigenous healthy food productivity with standardized recipes, food safety handling and food security management for preparing food for themselves as well as suitable for tourism consumption. In addition of this useful vegetarian calendar information, which is highly appropriate serving as a tool for their daily meal management.
\end{abstract}

\section{Introduction}

Ban Mae Kampong an upland village, is located in Huai Kaew sub-district, Mae On district, ChiangMai province. This village is in the east of Ching Mai, $50 \mathrm{kms}$ far, along the Mae On-Huai Kaew Road. The name of village, 'Mae Kampong' was from two words as, 'Mae' and 'Kampong'. Mae was from 'Mae-Nam' because of several streams passing through the village and also, there is the native flower (locally called "dok kampong") growing along these streams. The early settlers migrated from Doi Saket district, the nearby district in Chiang Mai province, to search land for tea cultivation. This area could be classified as hilly terrain or upland area with 1,300 meters above sea level. The village was further divided into six village clusters, covering an area of approximately 6.22 square kilometers, or 3,887.50 rai. The village area was classified into various land uses, 2,523.82 rai of the agricultural area, 930.38 rai of the forest area, and 433.30 rai of residential area.

Ban Pa Miang, an upland village, is located in Jae Sorn sub-district, Muang Pan district, Lampang province. This village has many groups of people from various places, Lanna people from Lampang and Khamu from Lao PDR and Marn or Burmese from Burma. In the past, the people of this village cut a lot of trees to grow rice and plant. In year 1988, the Thai government has declared this village as a conservation forest of Chae Son National Park which deforestation, hunting and gathering become illegal. The villagers have to behave according to the laws for surviving in the specific and 
small area leading to a change of the villagers' lifestyle. After that, the area for rice production and others plant have gone leading to buy the rice from others communities. Then eco-tourism has become an alternative way for them to survive in the national park area.

Villagers of these two villages have grown Assammica Teas in the lush forest area and used tea for the fermented tea or pickled tea (called Miang). In the fermented tea production cycle, the tea leaves can be harvested four times a year. However, in recent years, the villagers have turned to grow coffee by planting between the tea trees. The mainly income of this village obtained from Miang and coffee production. When the tourism was promoted leading to income increase.

Both Ban Mae Kampong and Ban Pa Miang are upland village, hillsides and slope, located in the moutain wich surrounding with shade of the big trees, small river and falls, The average temperature is around $10-18{ }^{\circ} \mathrm{C}$. It is an ideal place for travel and leisure, for example, hiking, a bike trip that explores community lifestyles. In addition, community members still maintain their cultural traditions as expressed through their dresses, language, food, cultural performances. Visitors can enjoy learning their culture.

From the reason above, these two villages have become the rural tourism destination as community based homestay ecotourism in 1999. The tourism was start with homestay and later on became ecotourism villages. The turists can access to this area all year round by private cars because there is no public transportation. In 2012, they have been encouraged to become health tourism community. So when tourists get into the community, food safety is very important for the tourists. The villagers must focus on food security for support people in their community and tourists' demand in the future.

This participatory study involved collaboration among community homestay members, community leaders, government health officers and direct participation of researchers in the object of study ("The Team") [1] "Participant observation is to some degree an essential element of all qualitative studies" [1]. The data were collected by interview, discussion groups, in-depth discussions, observations, and brainstorming with the following activities:

1. Academic researchers created a forum held with villagers and local leaders to explain the purpose of the research and project activities.

2. A focus group was held among the teams to analyze the problems and difficulties, limitations and potential of members who were involved in food preparation for tourists, including with food safety and food security.

3. Evaluated food safety knowledge and observed cooking practice.

4. Focus group in Food Security topic, survey and collected data.

The study was conducted between March - December 2012 at Moo 1, This study was conducted at two villages, Ban Mae Kampong, Mae-On, Chiang Mai and Ban Pa Miang, Muang-Parn, Lampang, Northern Thailand. These communities were supported by Thai government tourism ministry to develop their skills for creating and offering rural tourism, as health tourism. The research aimed to promote food safety management and food security in rural tourism community. Furthermore, the study was to establish a training center, a learning resource for other homestay groups, students, and general public. The study was carried out as a participatory study including seminars and workshops on hygienic condition in food management for the participants. The trainings also covered other food production related topics; including, introduction to food and nutrition, basic knowledge in food and health, food safety and sanitary management, healthy food concept, food display, food preparation, food preservation and practice, food purchase and food security.

Participants joined a focus group in which they collaborated in safety food preparation and management. They also took part in the SWOT analysis. Participants also collaborated in designing a Khan Tok set. In addition, they have learned from the workshops to improve the quality of healthy food; including, setting criteria for raw materials, using appropriate utensils in the production 
process. The participatory study method has various advantages, the immersion offers the researcher the opportunity to learn directly from his own experience of the setting' [1].

\section{Methodology}

\subsection{Procedure for collecting data}

Primary data was collected through interviews, discussion groups, in-depth discussion, observations and brainstorming. Data included transcripts of audio-taped meeting of community homestay members, community leader, and local government public health officers. Field data collection also included direct participation of researchers in every part of the rural tourism participation activities.

Secondary data was reviewed from books and researches on Lanna indigenous foods, northern Thai food style, traditional food service called "Khantoke", nutritional value of local plant food resources, and other literary work related to production of food safety and food security.

\subsection{Analyzing data on community food management for developing healthy khantoke food set, food safety and food security.}

Interview sheets were distributed to collect data on: personal information,cooking experience, healthy food concept and their knowledge in healthy Khantoke food. Other sources of data were from focus groups and evaluation of cooking skills and food display by participation technique, measurement of ingredients used for indigenious recipes. Data Analysis with respect to the following techniques;

1.) SWOT analysis regarding their Identity, physical strength, wisdoms and indigenious food culture, was conducted.

2.) Personal data; cooking skills and knowledge in healthy food and healthy Khantoke concept, was examined.

3.) Ingredients of indigenious dishes cooked by female residents were weighed for calculating nutritional value by INMUCAL Nutrition Software and quantity for food security management.

4.) Group discussions and focus groups on nutritive values of the indigenious dishes were held. Basic and applied knowledge in incorporating indigenous ingredients was provided to female residents of that two villagers.

5.) Data were analyzed by comparing various ways of food management to create the healthy indigenious food model. Workshops and trainings were held for community members who were involved in food preparation for tourists including with food safety and food security.

Evaluation of tourists' perception of Khantoke food. Evaluation was conducted by tourists who were journalists, government officers, and others.

\section{Results and discussion}

Food in the villages, Ban Mae Kampong and Ban Pa Miang was influenced by Lanna food culture, and prepared with local raw materials such as tea leaf, herbal, mushroom and chicken. This area is upland site of Assamica tea, used for the Miang production. Now communities also grow coffee 
between the tea trees for extra income. Moreover, rural tourism and homestay has become famous tourist destination. The results obtained from this study were shown below.

\subsection{The villages's potential and opportunity to become a rural tourism destination}

As the villages still maintain their traditional characteristics, such as being a tea leaf gardenning community, distinctive living with wildlife culture. It has high potential to be a tourist destination. Evaluation of the village's potential can be outlined as follows;

Potential of place. The villages are located in the moutain surrounded by many trees, small rivers and falls. The average temperature of $10-18{ }^{\circ} \mathrm{C}$, is good atmosphere for visitors

Potential of the group of women and its management. Female residents of the villages understand their duties clearly in the food preparation process.

Potential of good quality food resources. This community grows organic vegetables, especially chayote, banana flower, tea leaf and various types of herbs, The agricultural community not only grow sufficient amount of crops to accommodate tourists, such crops can also be developed into healthy menus or souvenirs for tourists.

Potential of the cooking members. The members could cook their indigenious food of unique taste. Additionally, Lanna food was classified according to eating styles. There were also Lanna dances performances during the Khantoke dinner. They had local musician groups and dances by young generation, picked tea dance and other Lanna dances, signal to the relay and cultural transmission.

Opportunity to promote indigenious food for rural tourism; The Team discovered local Food distinctiveness. The local food was cooked from raw materials available in the community area. Local community was eager to learn about healthy food by encouraging women groups who were involved in food preparation for tourists to learn how to cook healthy food and to develop a dining, hospitality and service models.

\subsection{SWOT analysis regarding the village's identity, strength, wisdoms and food culture}

The results of SWOT analysis indicated that woman groups had strengths and opportunities that might support development of healthy indigenous menu for tourists.

For weaknesses, they had limited knowledge on healthy eating and had no standardized recipes. As a consequence, this study set up the training programs to increase their knowledge in healthy cooking, food handling and food management.

\section{Strengths}

- Cooking expert.

- Healthy habit concern.

- Open-minded and ready to change.

- Maintain rural traditional culture.

- Local organic vegetable.

\section{Opportunity}

- Increase in the number of tourists.

- Healthy tourism model.

- Supported by the government.

\section{Weakness}

- Limited knowledge of healthy eating.

- Have no standard recipes.

- Preferences for salty taste.

- Limited land for farming.

\section{Threat}

-high workload in family care and farming. 


\subsection{Cooking experience, healthy food concepts, and healthy Khantoke food}

The group of women can cook using an indigenous food menu since teenage life and they learn how to cook. Mostly they cooked indigenous food for their family and some of them cooked indigenous's food for tourists in guest houses and homestays.

With regards to the perception of healthy food or healthy eating habits, this study set a focus group and used open-end questionnaires related to diet and health; what they could or could not eat and reasons; how their cooking skills were; their eating habits and personal hygiene. Also this study focused on the perception of eating portion. The results obtained were shown in Table 1.

Table 1. The level of knowledge in healthy eating perception of female residents.

\begin{tabular}{|c|c|}
\hline Healthy Eating Perception & Level \\
\hline Eating habit \& health & Good \\
Eat much \& trouble health & Good \\
Sugar and body weight \& diabetic & Good/fair \\
Low fat and blood lipid \& body weight & Good \\
Sodium and blood pressure & Good/fair \\
Enrichment nutrient diet & Fair \\
Good practice in cooking \& eating \& hygiene & Fair \\
Eating portion & Bad \\
\hline
\end{tabular}

From Table 1, they have a good level of understanding in eating and health, but they have an inappropriated understanding the level of sugar and salt consumption. They have no choice to select good nutrient sources. They had fair level of cooking practice, eating habits and personal hygiene. They have consumed a lot of saturated fatty acid from pork and Hang-lay dish without knowledge of eating portion properly.

Table 2. The level of knowledge in food safety of female residents.

\begin{tabular}{|c|c|c|}
\hline Food safety knowledge & Knowledge & Observe \\
\hline Cooking place & Fair & Poor \\
Cooking utensil & Good & Fair \\
Cleaning raw material & Fair & Fair \\
Food container selection & Fair & Fair \\
Food handling & Good & Fair \\
Personal hygiene & Good & Fair \\
\hline
\end{tabular}


From Table 2, although the female residents got a good level of knowledge, they have not followed the practical standard in food safety from the observation data. The knowledge and standard practice are very important to prepare tourists food. This study could improve their knowledge in food safety by teaching and collaboration practice in food safety topic.

\subsection{Developing healthy standard indigenous recipe cookbook}

The group of women cooked their own indigenous dishes. This study measured,weighed ingredients and calculated the nutritional value of local food by INMUCAL Nutrition Software and recommend healthy indigenous food recipes by decreasing amount of sodium, fat and cholesterol, reducing/replacing some ingredients, adding good source of fiber, preparing appropriate serving size and setting indigenous menu based on nutritional value and writing standard recipes (standard household measuring); for example, decrease sodium content from ingredient, use local vegetables in their menus. Moreover they can use this cook book to calculate the quantity of raw materials for preparing food for tourists, as food security management.

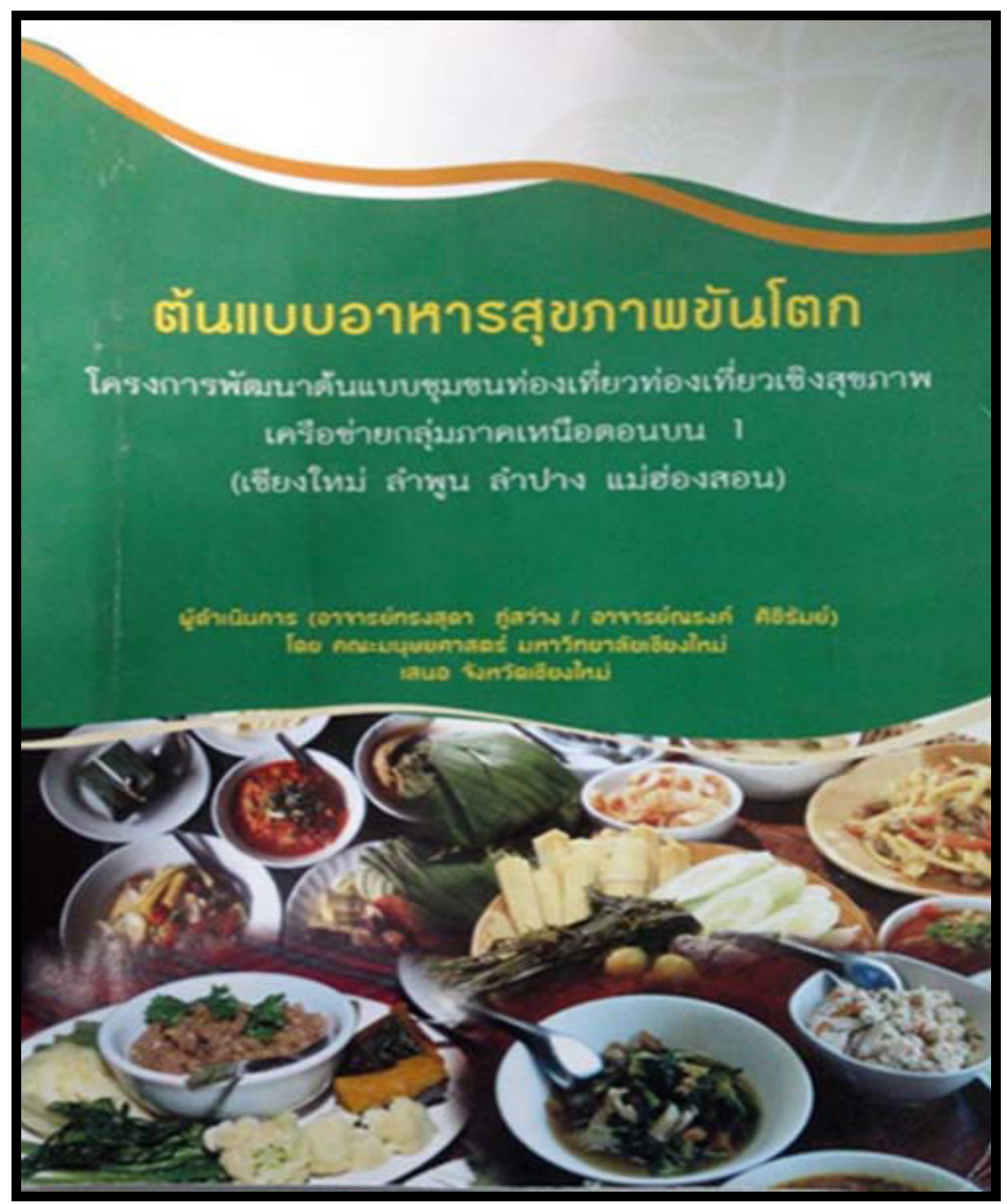

Figure 1. The standard indigenous menus cookbook 


\subsection{Community collaboration in food security management for tourism}

Villagers of the two communities have collaborated for food security through seasonal food calendar of the community in order to know about the types and amounts of vegetables and fruits which are available in the communities. The vegetables and fruits are classified by type that can be grown such as chayote, tea, pumpkin, ivy gourd, chili and herbs and that can be obtained from natural sources nearby such as bamboo shoot, banana stalk, banana blossom, etc. There is also food to be purchased from outside that is not available in the community such as rice and condiments such as fermented fish, shrimp paste, fish sauce, and others.

Concerning the management for food security, the villagers have prepared to grow the vegetables in front of the homes for their own consumption in the buckets such as onions, celery, lettuce as well as growing in the fence as chayote, ivy gourd, galangal, lemon grass, kaffir lime leaves, etc., in order to increase the amount of vegetables enough for tourists and for the family. The villagers also use the raw materials available in the community to prepare food to tourists such as banana blossom, banana of the banana stalk, shoot and fruit of chayote and a list of menu from tea leaves. This can reduce the cost in buying food and establish an identity for the food that impresses the tourists. Rice is available in large quantities for bargaining.

\section{Conclusion}

The villagers of both Ban Mae Kampong and Ban Pa Miang communities can manage food to support rural tourism by using the standard indigenous recipe cookbook and understanding all stages of food safety for tourists. Khantoke set has been used to serve food for impressing the tourists. Regarding food security in the community, more raw materials have been grown and seasonal raw materials have been used. The knowing an increasing number of tourists in the community, the villagers can forecast and manage to purchase in large volume of raw materials leading to a cost reduction occurring in the future. Therefore, the food safety and food security are an important factor used for promoting the sustainable rural tourism community.

\section{References}

1. C. Marshall, G. B. Rossman, Designing qualitative research, California: Sage Publications, (1999)

2. T. Auksorntub, Nutritive Values and Fiber of Lanna Food, Master of Science (Nutrition Education), ChiangMai university, ChiangMai, Thailand, (in Thai) (2006)

3. P. Boonmakard, The Study of Traditional Yong Foods, Master of Science (Nutrition Education), ChiangMai university, ChiangMai, Thailand. (in Thai) (2001)

4. P. Kantaruksa, Comparison of Nutritive Values Between Chemical Analysis and Calculation From Thai Food Composition Table, Master of Science (Nutrition Education), ChiangMai university, ChiangMai, Thailand, (in Thai) (2004)

5. K. Kaewtep, Self-reliance: the potential in the development of rural areas, Catholic Council of Thailand for Development, Bangkok, (in Thai) (1987)

6. C. Legkerm, Nutritional Value and Havesting Inbox of Some Locally Grown Vegetables in ChiangMai, Master of Science (Teaching Biology), ChiangMai university, ChiangMai, Thailand, (in Thai) (2009)

7. M. B. Mile, A. M. Huberman, Qualitative data analysis: An expanded, Thousand Oaks, CA: Sage, (1994)

8. G. E. Mills, Action research: A guide for the teacher researcher, Pearson (2007) 
9. S. Nimsakul, et al, Lanna food and wisdom in health care, ChiangMai, Thailand,(in Thai) (2003)

10. C. Robson, Real world research: A resource for social scientists and practitioner-researchers, Oxford: Blackwell Publications, (2002)

11. N. Suton, Study of Zinc and Copper Content in Local Native Vegetables ChiangMai Province. Master of Science (Nutrition Education), ChiangMai university, Thailand. (in Thai) (2002)

12. P. Valaisatein, S. Ob-oon, C. Hasannaree, Process and Techniques for Community Developer, The Thailand Research Fund, Bangkok,(in Thai) (2003)

13. R. Wongkamolshun, Num-prik-ta-dang a native food for health from Thai herbs of shallot, garlic and chilli with fribrinolytic promotion, Assiciated Med. ChinagMai university, Thailand, (in Thai)(2010) 